\title{
Migration and geographic variations in blood pressure in Britain
}

\author{
Jonathan Elford, Andrew Phillips, A G Thomson, A G Shaper
}

\begin{abstract}
Objective-To evaluate the relative contributions of factors acting at different stages in life to regional differences in adult blood pressure.

Design-Prospective cohort study (British regional heart study).

Setting-One general practice in each of 24 towns in Britain.

Subjects-7735 Men aged 40-59 years when screened in 1978-80 whose geographic zone of birth and zone of examination were classified as south of England, midlands and Wales, north of England, and Scotland. Non-migrants $(n=3144)$ were born in the town where they were examined; internal migrants $(n=4147)$ were born in Great Britain but not in the town where they were examined; and international migrants $(n=422)$ were born outside Great Britain.
\end{abstract}

Main outcome measures-Systolic and diastolic blood pressures and height.

Results-Regardless of where they were born, men living in the south of England had lower mean blood pressures than men living in Scotland $(142 \cdot 5 / 80 \cdot 1 v 148 \cdot 1 / 85 \cdot 2 \mathrm{~mm} \mathrm{Hg})$. The effects of the place of birth and place of examination on adult blood pressure were examined in a multiple regression model. For internal migrants the modelled increase in mean systolic blood pressure across adjacent zones of examination was $2 \cdot 1 \mathrm{~mm} \mathrm{Hg} \mathrm{(95 \%}$ confidence interval 1.3 to 2.9 ); for adjacent zones of birth the corresponding increase was $0.1 \mathrm{~mm} \mathrm{Hg}$ $(-0.7$ to 0.7$)$. The place of examination seemed to be a far more important determinant of mean adult blood pressure than the place of birth. Height is an accepted marker of genetic and early life influences. Regional differences in height were therefore analysed to test whether the multiple regression model could correctly distinguish between the influence of place of birth and place of examination. As expected, men born in Scotland were shorter on average than men born in the south of England irrespective of where they lived in Britain $(172.6 \mathrm{~cm} v$ $175 \cdot 1 \mathrm{~cm}$ for internal migrants).

Conclusion-Regional variations in blood pressure were strongly influenced by where the men had lived for most of their adult lives rather than by where they were born and brought up. Among middle aged men, factors acting in adult life seemed to be more important determinants of regional differences in blood pressure than those acting early in life such as genetic inheritance, intrauterine environment, and childhood experience.

\section{Introduction}

Substantial geographic variations in adult blood pressure have been reported within Britain. A threefold difference in the prevalence of hypertension was found among middle aged men in the 24 towns of the British regional heart study, with a trend towards higher rates in northern England and Scotland.'
Similar regional variations have also been described in women of the same age. ${ }^{2}$ The geographic gradient in blood pressure raises several controversial questions. Does this gradient reflect earlier geographic differences in the intrauterine environment? Are regional differences in adult blood pressure established during infancy? To what extent does the adult environment govern blood pressure in middle age and beyond? And, what is the contribution of genetic make up to adult blood pressure? There is, in fact, considerable debate about whether high blood pressure in middle age is established during adult life, ${ }^{3}$ in childhood, ${ }^{4}$ or indeed in utero. ${ }^{5}$ Consequently, explanations for the geographic gradient in adult blood pressure in Britain remain contentious.

Regional variations in height have also been described within Britain. In a recent survey of British adults aged 16-64 men and women living in Scotland were on average shorter than those living in the south of England; people living in the midlands and the north of England were of intermediate height. ${ }^{6}$ It is well established that genetic factors and environmental circumstances during childhood determine adult height. Therefore geographic differences in adult height in Britain probably reflect earlier regional variations in the prenatal and infant environments as well as in genetic make up.

We examined geographic differences in both blood pressure and height in middle aged British men according to their place of birth and place of examination. Migration into and within Britain allows the distinction to be drawn between the role of genetic make up and influences during early life on the one hand and the role of the adult environment on the other. ${ }^{8}$

\section{Subjects and methods}

The British regional heart study is a prospective investigation of ischaemic heart disease among 7735 men aged 40-59 at entry into the study. The criteria for selecting the towns, general practices, and subjects, as well as the method of collecting data, have been published. ${ }^{9}{ }^{10}$ In brief, the men were randomly selected from one general practice in each of 24 towns in England, Wales, and Scotland. All standard regions were included. Towns were chosen that reflected known geographic variations in mortality from cardiovascular disease and, wherever possible, were representative of the region in socioeconomic terms. No attempt was made to exclude subjects with cardiovascular disorders, and the overall response rate was $78 \%$. A team of three trained nurses examined the men when they enrolled for the investigation between January 1978 and June 1980.

Blood pressure and height-The London School of Hygiene sphygmomanometer with a standard adult cuff was used to measure blood pressure twice in succession with the subject seated, his arm supported on a cushion. Diastolic blood pressure was recorded at
Correspondence to: Dr Elford.

BrMed f 1990;300:291-5 
the disappearance of Korotkoff's sounds (phase V). The mean of the two blood pressure readings adjusted for interobserver variation ${ }^{11}$ was used for the analysis. Data on systolic pressure were available for 7727 men and data on diastolic pressure for 7725 . Height was measured without shoes by using a Harpenden Stadiometer with digital meter to the nearest millimetre. Data on height were available for 7733 men.

Migration-All men were asked their place of birth and for how long they had lived in the town where they

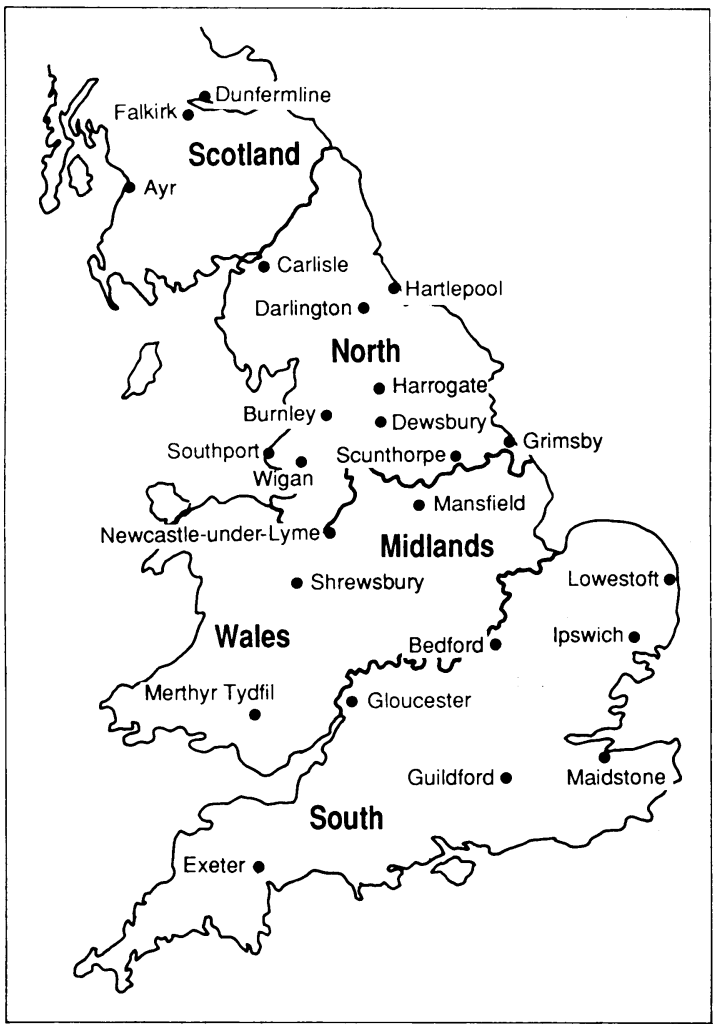

Twenty four towns and four regions of British regional heart study

TABLE, I-Internal migrants classified by their geographic zone of examination and zone of birth ${ }^{\star}$

\begin{tabular}{lrrrrrr}
\hline & \multicolumn{4}{c}{ Zone of examination } \\
\cline { 2 - 6 } Zone of birth & South & $\begin{array}{c}\text { Midlands } \\
\text { and Wales }\end{array}$ & North & Scotland & Total \\
\hline South & 985 & 85 & 210 & 42 & 1322 \\
Midlands and Wales & 151 & 425 & 180 & 12 & 768 \\
North & 173 & 131 & 1113 & 26 & 1443 \\
Scotland & 48 & 24 & 95 & 411 & 578 \\
\hline Total & 1357 & 665 & 1598 & 491 & 4111 \\
\hline
\end{tabular}

^Exact place of birth in Great Britain not known for 36 internal migrants.

TABLE II -Mean (SEM) systolic blood pressures $(\mathrm{mm} \mathrm{Hg})$ by geographic zone of examination and migration

\begin{tabular}{lccrrr}
\hline \multicolumn{5}{c}{ Zone of examination } \\
\cline { 2 - 4 } & South & $\begin{array}{c}\text { Midlands } \\
\text { and Wales }\end{array}$ & North & Scotland & All men \\
\hline All men & $142 \cdot 5(0 \cdot 4)$ & $144 \cdot 2(0 \cdot 6)$ & $146 \cdot 5(0 \cdot 4)$ & $148 \cdot 1(0 \cdot 7)$ & $145 \cdot 2(0 \cdot 2)$ \\
Non-migrants & $144 \cdot 4(0 \cdot 8)$ & $147 \cdot 2(1 \cdot 0)$ & $148 \cdot 1(0 \cdot 5)$ & $147 \cdot 3(1 \cdot 9)$ & $147 \cdot 0(0 \cdot 4)$ \\
Internal migrants & $141 \cdot 9(0 \cdot 5)$ & $142 \cdot 3(0 \cdot 8)$ & $145 \cdot 2(0 \cdot 5)$ & $148 \cdot 7(0 \cdot 9)$ & $144 \cdot 0(0 \cdot 3)$ \\
International migrants & $140 \cdot 0(1 \cdot 5)$ & $140 \cdot 8(3 \cdot 0)$ & $144 \cdot 8(1 \cdot 9)$ & $150 \cdot 1(4 \cdot 0)$ & $142 \cdot 7(1 \cdot 1)$ \\
\hline
\end{tabular}

TABLE III-Mean (SEM) diastolic blood pressures ( $\mathrm{mm} \mathrm{Hg}$ ) by geographic zone of examination and migration

\begin{tabular}{lccccc}
\hline & \multicolumn{5}{c}{ Zone of examination } \\
\cline { 2 - 5 } & South & $\begin{array}{c}\text { Midlands } \\
\text { and Wales }\end{array}$ & North & Scotland & All men \\
\hline All men & $80 \cdot 0(0 \cdot 3)$ & $80 \cdot 1(0 \cdot 4)$ & $83 \cdot 7(0 \cdot 2)$ & $85 \cdot 2(0 \cdot 5)$ & $82 \cdot 2(0 \cdot 2)$ \\
Non-migrants & $80 \cdot 5(0 \cdot 5)$ & $80 \cdot 5(0 \cdot 6)$ & $84 \cdot 2(0 \cdot 3)$ & $85 \cdot 2(0 \cdot 7)$ & $83 \cdot 0(0 \cdot 2)$ \\
Internal migrants & $79 \cdot 9(0 \cdot 4)$ & $79 \cdot 7(0 \cdot 5)$ & $83 \cdot 2(0 \cdot 3)$ & $85 \cdot 2(0 \cdot 6)$ & $81 \cdot 8(0 \cdot 2)$ \\
International migrants & $79 \cdot 1(0 \cdot 9)$ & $80 \cdot 2(2 \cdot 1)$ & $83 \cdot 7(1 \cdot 0)$ & $86 \cdot 4(2 \cdot 4)$ & $81 \cdot 5(0 \cdot 7)$ \\
\hline
\end{tabular}

were examined. With this information the men were allocated to three groups. The first group $(n=3144)$ contained men who were born in the town where they were examined (non-migrants). These men had lived in the same town for most, if not all, of their lives. The second group $(n=4147)$ comprised men who were born in Great Britain but not in the town of examination (internal migrants). On average these men had lived in their town of examination for 24 years. The smallest group $(n=422)$ consisted of men who were born outside Great Britain (international migrants). They had lived in their town of examination for 20 years on average. Information on the migration state of 22 men was not available.

Geography-Britain has been divided into four zones according to the established geographic trend in mortality from cardiovascular disease. ${ }^{12} 15$ These four geographic zones are the south of England (2280 men from the British regional heart study; $29.5 \%$ of the sample), the midlands and Wales (1208 men; $15 \cdot 6 \%)$, the north of England (3285 men; $42 \cdot 5 \%$ ), and Scotland (962 men; 12.4\%) (figure). Men born in Britain were also classified by their geographic zone of birth as follows: south of England (2032 men; 26.3\% of sample), the midlands and Wales (1250 men; 16.2\%), the north of England (2973 men; 38.4\%), and Scotland (1000 men; $12 \cdot 9 \%$ ). By definition, all the non-migrants were born and examined in the same geographic zone-indeed, the same town. In addition, $71 \cdot 4 \%$ of the internal migrants ( 2934 men) were also born in their geographic zone of examination but not in the town where they entered the British regional heart study (within zone migrants). This left 1177 internal migrants $(28.6 \%)$ who were born and examined in different geographic zones (between zone migrants). For 36 internal migrants the exact place of birth in Great Britain was not known (table I). Too few migrants were born in any one town or country to allow a finer geographic breakdown by place of birth.

Statistical methods-The relations between geographic location, blood pressure, and height in the cohort from the British regional heart study were analysed by a linear regression model using the PROC GLM program in the SAS statistical package. ${ }^{13}$ To test for a geographic trend in blood pressure the zones of examination and birth were fitted to the model with values 1 (south), 2 (midlands and Wales), 3 (north), and 4 (Scotland). The model compared mean blood pressure in any one geographic zone with that in its immediate neighbour to the south, assuming an equal change in mean blood pressure across each zone boundary. To test for a geographic trend in height the zones were fitted to the model with values 1 (south), 2 (midlands, Wales, and north), and 3 (Scotland), in accordance with the reported geographic gradient in height in Great Britain. ${ }^{6}$ This model also assumed an equal change in mean height across each of these boundaries.

\section{Results}

GEOGRAPHIC DIFFERENCES IN BLOOD PRESSURE

Mean systolic and diastolic blood pressures were calculated for each geographic zone of examination, both for all men and for each migration category (nonmigrant, internal migrant, and international migrant) (tables II and III). For the study population as a whole mean systolic and diastolic blood pressures showed pronounced gradients across the geographic zones that increased from the south up to Scotland. There was a difference of nearly $6 \mathrm{~mm} \mathrm{Hg}$ in systolic pressure and $5 \mathrm{~mm} \mathrm{Hg}$ in diastolic pressure between men examined in Scotland and those examined in the south of England. A similar geographic gradient in mean blood pressure (systolic and diastolic) was found among 
TABLE IV-Mean (SEM) systolic blood pressures $(\mathrm{mm} \mathrm{Hg}$ ) in internal migrants by geographic zone of examination and zone of birth

\begin{tabular}{lccccc}
\hline & \multicolumn{5}{c}{ Zone of examination } \\
\cline { 2 - 5 } Zone of birth & South & $\begin{array}{c}\text { Midlands } \\
\text { and Wales }\end{array}$ & North & Scotland & $\begin{array}{c}\text { All } \\
\text { migrants }\end{array}$ \\
\hline South & $141 \cdot 7(0 \cdot 6)$ & $137 \cdot 9(2 \cdot 4)$ & $145 \cdot 1(1 \cdot 5)$ & $156 \cdot 7(3 \cdot 5)$ & $142 \cdot 5(0 \cdot 6)$ \\
Midlands and Wales & $143 \cdot 4(1 \cdot 6)$ & $143 \cdot 5(1 \cdot 0)$ & $143 \cdot 1(1 \cdot 5)$ & $144 \cdot 6(7 \cdot 5)$ & $143 \cdot 4(0 \cdot 7)$ \\
North & $140 \cdot 9(1 \cdot 4)$ & $142 \cdot 2(1 \cdot 8)$ & $145 \cdot 6(0 \cdot 6)$ & $153 \cdot 0(4 \cdot 1)$ & $144 \cdot 9(0 \cdot 5)$ \\
Scotland & $143 \cdot 1(3 \cdot 2)$ & $138 \cdot 0(2 \cdot 6)$ & $143 \cdot 9(1 \cdot 9)$ & $147 \cdot 7(1 \cdot 0)$ & $146 \cdot 3(0 \cdot 9)$ \\
All internal migrants & $141 \cdot 8(0 \cdot 5)$ & $142 \cdot 2(0 \cdot 8)$ & $145 \cdot 2(0 \cdot 5)$ & $148 \cdot 6(1 \cdot 0)$ & $144 \cdot 0(0 \cdot 3)$ \\
\hline
\end{tabular}

TABLE $\mathrm{v}-$ Mean (SEM) diastolic blood pressures $(\mathrm{mm} \mathrm{Hg})$ in internal migrants by geographic zone of examination and zone of birth

\begin{tabular}{|c|c|c|c|c|c|}
\hline \multirow[b]{2}{*}{ Zone of birth } & \multicolumn{4}{|c|}{ Zone of examination } & \multirow{2}{*}{$\begin{array}{c}\text { All } \\
\text { internal } \\
\text { migrants }\end{array}$} \\
\hline & South & $\begin{array}{l}\text { Midlands } \\
\text { and Wales }\end{array}$ & North & Scotland & \\
\hline South & $79 \cdot 9(0 \cdot 4)$ & $77 \cdot 9(1 \cdot 3)$ & $81 \cdot 7(0 \cdot 9)$ & $88 \cdot 5(2 \cdot 1)$ & $80 \cdot 3(0 \cdot 4)$ \\
\hline Midlands and Wales & $80 \cdot 3(1 \cdot 1)$ & $80 \cdot 2(0 \cdot 6)$ & $81.9(0.9)$ & $84 \cdot 6(4 \cdot 6)$ & $80 \cdot 7(0.5)$ \\
\hline North & $79.8(0.9)$ & $79 \cdot 8(1 \cdot 0)$ & $83 \cdot 6(0 \cdot 4)$ & $85 \cdot 3(2 \cdot 4)$ & $82 \cdot 9(0 \cdot 3)$ \\
\hline Scotland & $80 \cdot 1(1.9)$ & $77 \cdot 0(2 \cdot 1)$ & $84 \cdot 7(1 \cdot 4)$ & $84.9(0 \cdot 7)$ & $84 \cdot 2(0 \cdot 6)$ \\
\hline All internal migrants & $79.9(0 \cdot 4)$ & $79 \cdot 7(0.5)$ & $83 \cdot 2(0 \cdot 3)$ & $85 \cdot 2(0 \cdot 6)$ & $81 \cdot 8(0 \cdot 2)$ \\
\hline
\end{tabular}

TABLE VI-Mean $(S E M)$ heights (cm) of internal migrants by geographic zone of examination and zone of birth

\begin{tabular}{|c|c|c|c|c|c|}
\hline \multirow[b]{2}{*}{ Zone of birth } & \multicolumn{4}{|c|}{ Zone of examination } & \multirow{2}{*}{$\begin{array}{c}\text { All } \\
\text { internal } \\
\text { migrants }\end{array}$} \\
\hline & South & $\begin{array}{l}\text { Midlands } \\
\text { and Wales }\end{array}$ & North & Scotland & \\
\hline South & $175 \cdot 0(0 \cdot 2)$ & $175 \cdot 4(0 \cdot 7)$ & $175 \cdot 3(0 \cdot 4)$ & $175 \cdot 3(1 \cdot 0)$ & $175 \cdot 1(0 \cdot 2)$ \\
\hline Midlands and Wales & $174 \cdot 3(0 \cdot 5)$ & $173.4(0.3)$ & $174.0(0.5)$ & $174 \cdot 3(1 \cdot 4)$ & $173 \cdot 7(0 \cdot 2)$ \\
\hline North & $174.6(0.5)$ & $174 \cdot 0(0 \cdot 5)$ & $174 \cdot 0(0 \cdot 2)$ & $173 \cdot 1(1 \cdot 1)$ & $174 \cdot 0(0 \cdot 2)$ \\
\hline Scotland & $172 \cdot 2(0 \cdot 9)$ & $173.9(1.4)$ & $172 \cdot 6(0 \cdot 6)$ & $172 \cdot 6(0 \cdot 3)$ & $172 \cdot 6(0.3)$ \\
\hline All internal migrants & $174 \cdot 8(0 \cdot 2)$ & $173 \cdot 8(0 \cdot 3)$ & $174 \cdot 1(0 \cdot 2)$ & $172 \cdot 9(0 \cdot 3)$ & $174 \cdot 1(0 \cdot 1)$ \\
\hline
\end{tabular}

non-migrants, internal migrants, and international migrants (tables II and III). Adjustment for age did not alter this geographic pattern.

\section{Geographic trend in blood pressure}

For the entire cohort the linear regression model described an increase in mean systolic blood pressure of $1.9 \mathrm{~mm} \mathrm{Hg}$ (95\% confidence interval 1.5 to 2.4 ) across each zone boundary. For mean diastolic blood pressure the model also described an increase of $1.9 \mathrm{~mm} \mathrm{Hg}$ (1.6 to 2.2$)$ across each zone boundary. On the whole, the model fitted the data well.

To test for a geographic trend within each migration category we fitted the linear regression model for each group separately. The modelled increases in mean systolic blood pressure across each zone boundary were $1.2 \mathrm{~mm} \mathrm{Hg}(0.5$ to 2.0$)$ for non-migrants; $2.0 \mathrm{~mm} \mathrm{Hg}$ $(1.8$ to 2.3$)$ for internal migrants; and $2.9 \mathrm{~mm} \mathrm{Hg}$ $(0.9$ to 4.9$)$ for international migrants. For mean diastolic blood pressure the corresponding modelled increases were $1.8 \mathrm{~mm} \mathrm{Hg}(1.4$ to 2.3$)$ for nonmigrants; $1.8 \mathrm{~mm} \mathrm{Hg}(1.4$ to 2.2$)$ for internal migrants; and $2.4 \mathrm{~mm} \mathrm{Hg}$ (1.2 to 3.6$)$ for international migrants. As the confidence intervals show, the test for a geographic trend in systolic and diastolic blood pressures was significant at the $5 \%$ level for all categories of migrant.

\section{Migration within Britain}

In table IV the diagonal (from top left to bottom right) contains migrants within the zone while the remaining cells are occupied by men who moved between zones. As migrants differ from non-migrants ${ }^{14}$ the latter have been excluded from this table. Within each geographic zone of birth - that is, looking along each row - men examined in the south of England had a lower mean systolic blood pressure than those examined in Scotland. In general, men examined in the north had intermediate mean systolic values. Within each geographic zone of examination - that is, looking down each column-there was no such consistent gradient by zone of birth. Similar findings were obtained for diastolic blood pressure (table V). The geographic zone of examination seemed to be a more important determinant of adult blood pressure than the geographic zone of birth.

Modelling the geographic zones of examination and birth

We simultaneously entered both the geographic zone of examination and the zone of birth into a multiple linear regression model. The modelled increase in mean systolic blood pressure for each zone of examination was $2 \cdot 1 \mathrm{~mm} \mathrm{Hg}(1 \cdot 3$ to $2 \cdot 9 ; \mathrm{p}=0 \cdot 0001)$; for each zone of birth the modelled increase was $-0.1 \mathrm{~mm} \mathrm{Hg}(-0.9$ to $0.7 ; \mathrm{p}=0.8)$. Controlling for age and social class in the multiple regression model did not change the relations between systolic blood pressure and place of birth or examination (the modelled increment in mean systolic blood pressure for zone of examination was $1.9 \mathrm{~mm} \mathrm{Hg}(1.2$ to 2.7 ; $\mathrm{p}=0.0001)$ and for zone of birth $-0.2 \mathrm{~mm} \mathrm{Hg}(-1.0$ to $0 \cdot 5 ; \mathrm{p}=0.6$ ) after adjusting for age and social class).

After controlling for age and social class in the multiple linear regression equation the modelled increments in mean diastolic blood pressure were $1.5 \mathrm{~mm} \mathrm{Hg}(1.0$ to $2.0 ; \mathrm{p}=0.0001)$ for zone of examination and $0.3 \mathrm{~mm} \mathrm{Hg}(-0.2$ to $0.8 ; p=0.3)$ for zone of birth. These estimates and their confidence intervals confirm that the geographic zone of examination is a more important determinant of adult systolic and diastolic blood pressure than the geographic zone of birth.

\section{GEOGRAPHIC DIFFERENCES IN HEIGHT}

Mean height was calculated for the internal migrants according to their place of birth and place of examination (table VI). Looking down the diagonal (top left to bottom right) men born and examined in the south were taller on average than those born and examined in Scotland $(175.0 \mathrm{~cm} v 172.6 \mathrm{~cm})$. Men born and examined in the midlands, Wales, and the north occupied an intermediate position. The top row in table VI shows that men born in the south of England who were examined in the north or in Scotland were on average as tall as those who were also born in the south and who remained there. Similarly, on looking along the next to bottom row at men who were born in Scotland the mean height of those who moved south was about the same as those who stayed in Scotland or the north of England. Men born in Scotland who settled in the midlands and Wales departed slightly from this pattern. None the less, within each geographic zone of examination (looking down the columns) those born in the south of England were taller on average than those born in Scotland. And, for the most part, men born in the north, midlands, and Wales were of intermediate height. The geographic zone of birth seemed to be a more important determinant of adult height than the geographic zone of examination.

\section{Modelling geographic zones of examination and birth}

Both the geographic zone of examination and the zone of birth were simultaneously entered into a multiple linear regression model. For zone of birth the modelled decrease in mean height was $1 \cdot 15 \mathrm{~cm}(0 \cdot 76$ to $1.54 ; p=0.0001)$; for zone of examination the modelled decrease was $0.11 \mathrm{~cm}(-0.52$ to $0 \cdot 30 ; p=0 \cdot 6)$. Controlling for age and social class in the multiple regression equation did not change the relations between adult height and place of birth or place of examination (after adjusting for age and social class the modelled decrease for zone of birth was $1.05 \mathrm{~cm}(0.66$ to $1.44 ; p=0.0001)$; and for zone of examination $-0.09 \mathrm{~cm}(-0.50$ to $0 \cdot 32 ; \mathrm{p}=0 \cdot 7)$ ). These estimates and their confidence intervals confirm that the geographic zone of birth is a 
more important determinant of adult height than the geographic zone of examination.

\section{Discussion}

REGIONAL VARIATIONS IN BLOOD PRESSURE IN BRITAIN

An appreciable geographic gradient in both systolic and diastolic blood pressure was found in middle aged men in the British regional heart study. Irrespective of where they were born, men living in the south of England had lower mean blood pressures (systolic and diastolic) than those living in Scotland. The place of examination - that is, residence - seemed to be a more important determinant of adult blood pressure than the place of birth.

Though the 24 towns in the British regional heart study did not constitute a random selection of towns in the different geographic zones, the geographic gradient in blood pressure in the study cohort is consistent with that described in official statistics on mortality from stroke. ${ }^{12}$ is In 1985 the standardised mortality ratios for stroke (International Classification of Diseases 430-438) for men aged 35-64 who died in the four geographic zones (south, midlands and Wales, north, and Scotland) were 82,110,120, and 138 respectively (England and Wales $=100$ ). Given the aetiological importance of hypertension for stroke, ${ }^{16}$ we would expect populations with high mortality from stroke to have higher mean blood pressures than populations with low mortality from stroke. This strongly suggests that the geographic gradient in blood pressure reported in the British regional heart study is to be found in all middle aged men living in Britain.

The findings among the migrants strongly suggest that the geographic differences in blood pressure among middle aged British men are determined by factors acting during adult life rather than by genetic constitution or intrauterine environment. If the geographic variations in adult blood pressure were genetically determined we would expect Scottish men to carry their raised blood pressure with them when they moved south and men born in the south of England to take their lower blood pressure with them to the north or Scotland. Equally, if geographic differences in the intrauterine environment made a substantial long term contribution to regional variations in adult blood pressure, the place of birth would be of greater importance than the place of examination. This was clearly not the case in the cohort from the British regional heart study.

Many of the internal migrants will have spent their childhood in the place where they were born before moving in later life to the town where they entered the British regional heart study (D Strachan, personal communication). If geographic differences in adult blood pressure were established during infancy we would expect the place where the men spent their childhood (which for most subjects was where they were born) to be a more important determinant of their adult blood pressure than where they were examined. This was not, however, the case in the British regional heart study.

A recent study suggested that population differences in blood pressure identified in middle age may be reflected early in childhood. ${ }^{+}$Our findings do not exclude the possibility that environmental factors acting during infancy produce geographic variations in children's blood pressure similar to those found among adults. If this were the case geographic differences in the blood pressures of non-migrants may well be established at an early age. Any geographic differences in blood pressure that are indeed present during infancy, however, might be modified in later life. This finding is consistent with other studies of migrants between communities with low and high blood pressure. ${ }^{178}$ Consequently, blood pressure differentials established during infancy need not persist inexorably into later adult life.

\section{REGIONAL DIFFERENCES IN BLOOD PRESSURE AND} HEIGHT

A geographic gradient in height was also found in the British regional heart study. Men examined in Scotland were shorter on average than those recruited in the south of England. The geographic gradient in height found in the British regional heart study is consistent with that reported in a national survey based on a representative sample of 10000 British adults aged 16-64 years examined in $1980 .{ }^{6}$ In that survey the mean heights of men were $174.4 \mathrm{~cm}$ (south), $173.5 \mathrm{~cm}$ (midlands and Wales), $173.5 \mathrm{~cm}$ (north), and $173.0 \mathrm{~cm}$ (Scotland).

For the internal migrants in the British regional heart study, the place of birth was the crucial determinant of their adult height, even after controlling for age and social class. Adult height is a marker of both genetic and early life influences, such as childhood nutrition and infection. ${ }^{7}$ Consequently, the geographic differential in height among internal migrants in the British regional heart study throws into sharp focus the presence of earlier regional variations in both prenatal and infant environments, as well as geographic differences in genetic make up. These regional variations in genetic characteristics and intrauterine and infant environments do not seem, however, to exert the same strong influence on the geographic gradient in adult blood pressure as they do on adult height. For blood pressure in adults the place of residence in middle age is more important than the place of birth and upbringing. This finding is consistent with our earlier report on migration and geographic variations in ischaemic heart disease. ${ }^{19}$ We found that among migrants regional variations in the risk of having a heart attack were strongly influenced by factors acting in adult life. Changes in blood pressure with migration may therefore partly explain the corresponding modification in the risk of having a heart attack in Britain

Regional variations in alcohol consumption, ${ }^{20}$ physical activity, ${ }^{21}$ and socioeconomic circumstances $^{1022}$ will all contribute to the pronounced geographic gradient in adult blood pressure described in this paper. Interestingly, this gradient cannot be explained by regional differences in the proportion of people being treated for high blood pressure. ${ }^{2}$ The identification of factors acting during adult life on blood pressure will provide an important insight into the determinants of hypertension in middle age. With this information public health initiatives may be formulated to reduce the prevalence of adult hypertension and its associated morbidity throughout the whole of Britain.

The British Regional Heart Study Group is a British Heart Foundation Research Group and also receives support from the Department of Health and the Chest, Heart and Stroke Association. We thank Dr Peter Whincup for his helpful comments.

\footnotetext{
1 Shaper AG, Ashby D, Pocock SJ. Blood pressure and hypertension in middleaged British men. F Hypertens 1988:6:367-74.

Bruce NG, Cook DG, Shaper AG, Thomson AG. Geographical variations in blood pressure in British men and women. 7 Clin Epidemiol (in press)

3 Pickering G. The inheritance of arterial pressure. In: Stamler J, Stamler $R$, Pullman TN, eds. The epidemiology of hypertension. New York: Grune and Stratton, 1967.

4 Whincup PH, Cook DG, Shaper AG, MacFarlane DJ, Walker M. Blood Whincup PH, Cook DG, Shaper AG, MacFarlane DJ, Walker M. Blood
pressure in British children: associations with adult blood pressure and cardiovascular mortality. Lancel 1988 ;ii: $890-3$.

5 Barker DJP, Osmond C, Golding J, Kuh D, Wadsworth MEJ. Growth in utero, blood pressure in childhood and adult life, and mortality from cardiovascular disease. Br Med f 1989;298:564-7.

6 Knight I. The heights and weights of adults in Great Britain. London: HMSO,
} 1984 
7 Rona RJ. Genetic and environmental factors in the control of growth in childhood. Br Med Bull 1981;37:265-72.

8 Haenzel W. Studies of migrant populations. $\mathcal{F}$ Chronic Dis 1970;23:289-91.

9 Pocock SJ, Shaper AG, Cook DG, et al. British regional heart study: geographic variations in cardiovascular mortality, and the role of water quality. Br Med f 1980:280:1243-9.

10 Shaper AG, Pocock SJ, Walker M, et al. British regional heart study: cardiovascular risk factors in middle-aged men in 24 towns. $\mathrm{Br} \mathrm{Med} \mathcal{f}$ cardiovascular risk

11 Bruce NG, Shaper AG, Walker M, Wannamethee G. Observer bias in blood pressure studies $f$ Hypertens 1988:6:375-80.

2 Office of Population Censuses and Surveys. Mortality statistics: area. England and Wales 1985. London: HMSO, 1987. (Series DH5 No 12.)

13 SAS Institute. SAS user's guide: statistics version 5 edition. Cary, North Carolina: SAS Institute, 1985

14 Bentham G. Migration and morbidity; implications for geographical studies of disease. Soc Sci Med 1988;26:49-54.

15 Registrar General, Scotland. Annual report 1985. Edinburgh: HMSO, 1986.
16 Bulpitt CJ. The prognosis of essential hypertension. In: Bulpitt CJ, edt Epidemiology of hypertension. Amsterdam: Elsevier, 1985.

17 Marmot MG. Geography of blood pressure and hypertension. Br Med Bull $1984 ; 40: 380-6$

18 Cassel J. Studies of hypertension in migrants. In: Paul O, ed. Epidemiology and control of hypertension. New York: Stratton, 1975.

19 Elford J, Phillips AN, Thomson AG, Shaper AG. Migration and geographic variations in ischemic heart disease in Great Britain Lancet 1989;:343-6.

20 Shaper AG, Wannamethee G, Whincup PH. Alcohol and blood pressure in middle-aged British men. Fournal of Human Hypertension 1988;2:71-8.

21 Fagard R, M'Buyamba J-R, Staessen J, Vanhees L, Amery A. Physical activity and blood pressure. In: Bulpitt C, ed. Epidemiology of hypertension. Amsterdam: Elsevier, 1985.

22 Pocock SJ, Shaper AG, Cook DG, Phillips AN, Walker M. Social class differences in ischaemic heart disease in British men. Lancet 1987; ii $197-201$

(Accepted 27 November 1989)

\title{
Examination of fetuses after induced abortion for fetal abnormality
}

\author{
Jill Clayton-Smith, P A Farndon, Carole McKeown, Dian Donnai
}

Abstract

Objective-To determine the accuracy of midtrimester diagnosis of fetal abnormality by examination and investigation of fetuses after induced abortion.

Design-Prospective study over five years of fetuses aborted in the midtrimester because of abnormalities detected by ultrasonography and amniocentesis. Techniques included a full external examination by a clinical geneticist with experience in dysmorphology and other investigations including necropsy.

Setting-Regional genetic centre.

Participants-Clinicians working within the North Western region who wished to use the service offered.

Results-133 Fetuses were aborted because of abnormalities detected on ultrasonography and 115 because of abnormal findings on amniotic fluid analysis. In a further two cases fetal abnormality was diagnosed by molecular genetic and biochemical techniques. Among the fetuses with abnormal scans the pretermination diagnosis was changed or refined in a way which affected genetic counselling in 53 of 133 cases. Among the 115 fetuses diagnosed as abnormal by amniocentesis the pretermination diagnosis was confirmed in 112 cases and altered in three.

TABLE I-Routine observations on each midtrimester fetus

\begin{tabular}{ll}
\hline \multicolumn{1}{c}{ Fetus } & \multicolumn{1}{c}{ Placenta } \\
\hline Weight & Weight \\
Crown-rump length and crown-heel length & Macroscopic appearance \\
Occipitofrontal circumference & Number of cord vessels \\
Foot length, medial border & Length of cord \\
Inner and outer canthal distance & \\
External sex & \\
External appearance documenting structural & \\
abnormalities & \\
\end{tabular}

BrMed f 1990;300:295-7
Conclusion-Fetuses aborted because of abnormalities detected by screening should be examined by suitably experienced clinicians, both for accurate genetic counselling of the families and for quality control of the tests employed.

\section{Introduction}

An ultrasound scan in the midtrimester is now a routine part of antenatal care in most maternity hospitals. As technology improves and skill increases more fetal abnormalities are being recognised in the scans.' The number of amniocenteses performed also continues to rise, mainly as a result of chromosomal screening for high maternal age. These two types of screening procedure can detect serious fetal abnormalities and some parents will opt for termination of the pregnancy. ${ }^{2}$ In the North Western region we offer a service to examine fetuses aborted after a diagnosis of fetal abnormality. Many clinicians use the service but this study does not represent complete ascertainment, though virtually all fetuses aborted after amniocentesis diagnosis in the department are examined. We examined 250 fetuses aborted over five years because of abnormalities detected in the midtrimester and found that the pretermination diagnosis could often be changed or altered substantially in a way which affected genetic counselling. This paper summarises our findings.

\section{Subjects and methods}

Two hundred and fifty fetuses which had been aborted in the midtrimester because of fetal abnormality were received into the regional genetic centre over the five years 1982-7. In 115 cases the diagnosis had been made on amniocentesis samples and a further 133 fetuses had major abnormalities detected by ultrasonography. One fetus was aborted because of maternal phenylketonuria, and one was at high risk of carrying the gene for Huntington's chorea. All referring doctors were asked to give the pretermination diagnosis and to state by which method this had been made. Throughout this report the pretermination diagnosis is taken to be that on which the parents and obstetrician acted when deciding on termination of pregnancy. We request that fetuses are sent as soon after termination as possible in a dry, clean container. Table I lists the routine observations made in each case.

When noting the external appearance we take postmortem changes into account, as these may be mistaken for anomalies and may alter some measure- 